(2)

\section{OPEN ACCESS}

\title{
Use of rituximab in paediatric nephrology
}

\author{
Rajiv Sinha, ${ }^{1}$ Nirav Agrawal (10), ${ }^{2}$ Yuanxin Xue (i), ${ }^{3}$ Rahul Chanchlani (1), ${ }^{4}$ \\ Subal Pradhan, ${ }^{5}$ Rupesh Raina, ${ }^{2}$ Stephen D Marks ${ }^{6}{ }^{6,7}$
}

\begin{abstract}
- Additional material is published online only. To view, please visit the journal online (http://dx.doi.org/10.1136/ archdischild-2020-321211).

${ }^{1} \mathrm{ICH}$, Institute of Child Health, Kolkata, India

${ }^{2}$ Department of Nephrology, Akron Children's Hospital,

Akron, Ohio, USA

${ }^{3}$ Faculty of Health Sciences, McMaster University, Hamilton, Ontario, Canada

${ }^{4}$ Division of Pediatric

Nephrology, Department of Pediatrics, McMaster University, Hamilton, Ontario, Canada ${ }^{5}$ Department of Pediatrics, Sardar Vallabhbhai Patel Post Graduate Institute of Paediatrics(SVPPGIP), Cuttack, Odisha, India

${ }^{6}$ Department of Paediatric Nephrology, Great Ormond Street Hospital for Children NHS Foundation Trust, London, UK ${ }^{7} \mathrm{NIHR}$ Great Ormond Street Hospital Biomedical Research Centre, University College London Great Ormond Stree Institute of Child Health, London, UK
\end{abstract}

Correspondence to Dr Stephen D Marks, Department of Paediatric Nephrology, Great Ormond Street Hospital for Children NHS Foundation Trust, London WC1N 3JH, UK; markss2@gosh.nhs.uk

Received 19 November 2020 Revised 27 February 2021 Accepted 10 March 2021 Published Online First 10 June 2021

\section{Check for updates}

(C) Author(s) (or their employer(s)) 2021. Re-use permitted under CC BY-NC. No commercial re-use. See rights and permissions. Published by BMJ.

To cite: Sinha R, Agrawal N, Xue Y, et al. Arch Dis Child 2021;106:1058-1065.

\section{ABSTRACT}

Rituximab is a chimeric monoclonal antibody capable of depleting B cell populations by targeting the CD20 antigen expressed on the cell surface. Its use in oncology, initially in B cell lymphoma and post-transplant lymphoproliferative disorders, predates its current utility in various fields of medicine wherein it has become one of the safest and most effective antibody-based therapies. It was subsequently found to be effective for rheumatological conditions such as rheumatoid arthritis and antineutrophil cytoplasmic antibody-associated vasculitis. Over the past decade, rituximab has generated a lot of interest in nephrology and has become an emerging or accepted therapy for multiple renal conditions, including systemic lupus erythematosus, lupus nephritis, vasculitis, nephrotic syndrome and in different scenarios before and after kidney transplantation. This review outlines its current use in paediatric nephrology practice, focusing on the knowledge required for general paediatricians who may be caring for children prescribed this medication and reviewing them on a shared care basis.

\section{INTRODUCTION}

Rituximab is a monoclonal antibody against the CD20 antigen on B lymphocytes, which was originally used successfully as intravenous treatment for $\mathrm{B}$ cell lymphoma in adults and children. ${ }^{1}$ Over the last two decades, it has been used more frequently in children with different kidney diseases, including systemic lupus erythematosus (SLE) and lupus nephritis, antineutrophil cytoplasmic antibodyassociated vasculitis (AAV), nephrotic syndrome (NS) and kidney transplantation (KT). This review will investigate the scientific basis for the use of intravenous rituximab, with a focus on paediatric data accumulating over the last decade.

\section{MOLECULAR STRUCTURE OF RITUXIMAB}

Rituximab is a chimeric IgG1 kappa type immunoglobulin antibody that induces B cell lysis. It is composed of a human constant sequence ( $\mathrm{Fc}$ region) and mouse anti-CD20 variable sequence (Fab region) (figure 1A). It binds directly to the CD20 antigen, which is a non-glycosylated tetraspanning phosphoprotein embedded in the cell membrane, restricted to cells of $\mathrm{B}$ cell lineage including pre-B cells, memory cells and B lymphocytes found in tissues such as the white pulp of the spleen and lymph nodes. Healthy plasma cells, pro-B cells or other normal tissues lack this specific antigen. ${ }^{2}$ After binding to rituximab, CD20 is translocated into lipid rafts, where it signals through tyrosine kinases, mitogen-activated protein kinases and phospholipase $\mathrm{C} \gamma$, to mediate the inhibition of $\mathrm{B}$ cell growth or induce apoptosis. ${ }^{34}$

\section{PHARMACODYNAMICS AND PHARMACOKINETICS}

Rituximab is administered intravenously, available as a clear, colourless, odourless and preservativefree liquid in $100 \mathrm{mg}(10 \mathrm{~mL})$ or $500 \mathrm{mg}(50 \mathrm{~mL})$ single-use vials at a concentration of $10 \mathrm{mg} / \mathrm{mL}$. The product (brands include Rituxan and MabThera) is formulated in $9.0 \mathrm{mg} / \mathrm{mL}$ sodium chloride, $7.35 \mathrm{mg} /$ $\mathrm{mL}$ sodium citrate dihydrate, $0.7 \mathrm{mg} / \mathrm{mL}$ polysorbate and sterile water, with the $\mathrm{pH}$ adjusted to 6.5 similar to other biosimilars available in the market. ${ }^{15}$ After administration, the rituximab antibody is disseminated throughout the body and binds to the CD20 antigen on normal or abnormal $B$ cells. Rituximab is a large molecule, and pharmacokinetic studies have shown that it follows a two-compartment model with a terminal half life of 19-22 days. ${ }^{6}$ Although serum levels achieved have been found to be similar irrespective of age or dose $\left(375 \mathrm{mg} / \mathrm{m}^{2}\right.$ or $\left.1000 \mathrm{mg} / \mathrm{m}^{2}\right)$, multiple repeated doses have been shown to increase its serum level as well as prolong serum half-life..$^{7-9}$ Continuation of maintenance immunosuppression following rituximab infusion has been shown to further prolong CD19 depletion. ${ }^{10}$ As rituximab elimination through urine is increased in significant proteinuria, it is usually advisable to achieve a complete remission prior to its administration. However, this may not always be possible as is the case with steroid-resistant nephrotic syndrome (SRNS), and repeated doses have been suggested to be useful in this cohort. ${ }^{11}$

\section{MECHANISM OF ACTION}

Rituximab mediates its effect through various mechanisms, which allow it to be potentially useful across a wide range of kidney disorders:

I. B cell depletion.

II. Indirect/direct effect on T cells.

III. Direct podocyte activity.

\section{B cell depletion occurs through three main pathways}

Antibody-dependent cell-mediated cytotoxicity (ADCC) The rituximab antibody binds to the CD20 receptor through its $\mathrm{Fab}$ portion while exposing its $\mathrm{Fc}$ region for effector cells like natural killer cells, macrophages and neutrophils (figure 1B). ${ }^{12} 13$

\section{Complement-dependent cytotoxicity (CDC)}

Similar to ADCC, B cell lymphocytes form complexes with the rituximab antibody and activate 


\section{A. Rituximab Molecular Structure}

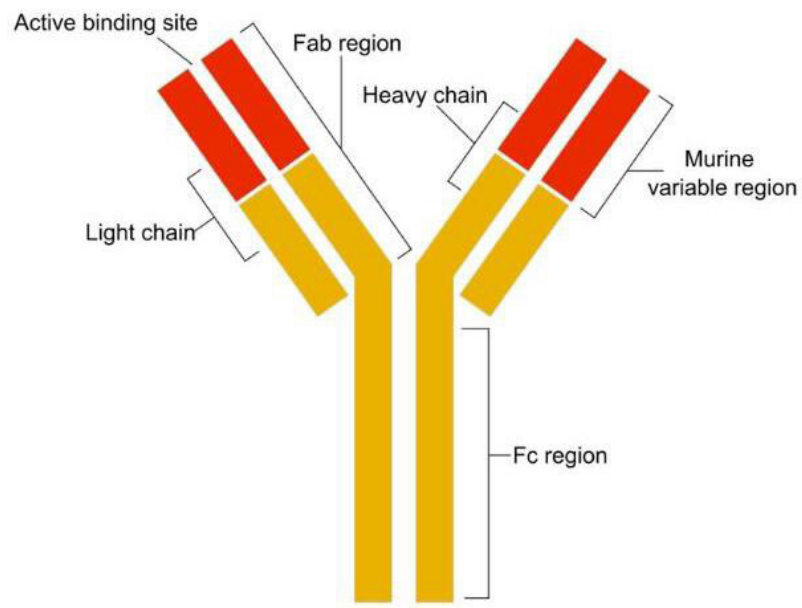

Human IgG monoclonal

\begin{tabular}{c|c|c|c} 
Heavy chain & Light chain & Molecular weight & $\begin{array}{c}\text { Binding affinity for } \\
\text { CD20 antigen }\end{array}$ \\
\hline 451 amino acids (aa) & 213 aa & $145 \mathrm{kD}$ & $80 \mathrm{nM}$
\end{tabular}

B. Various mechanism of action for Rituximab

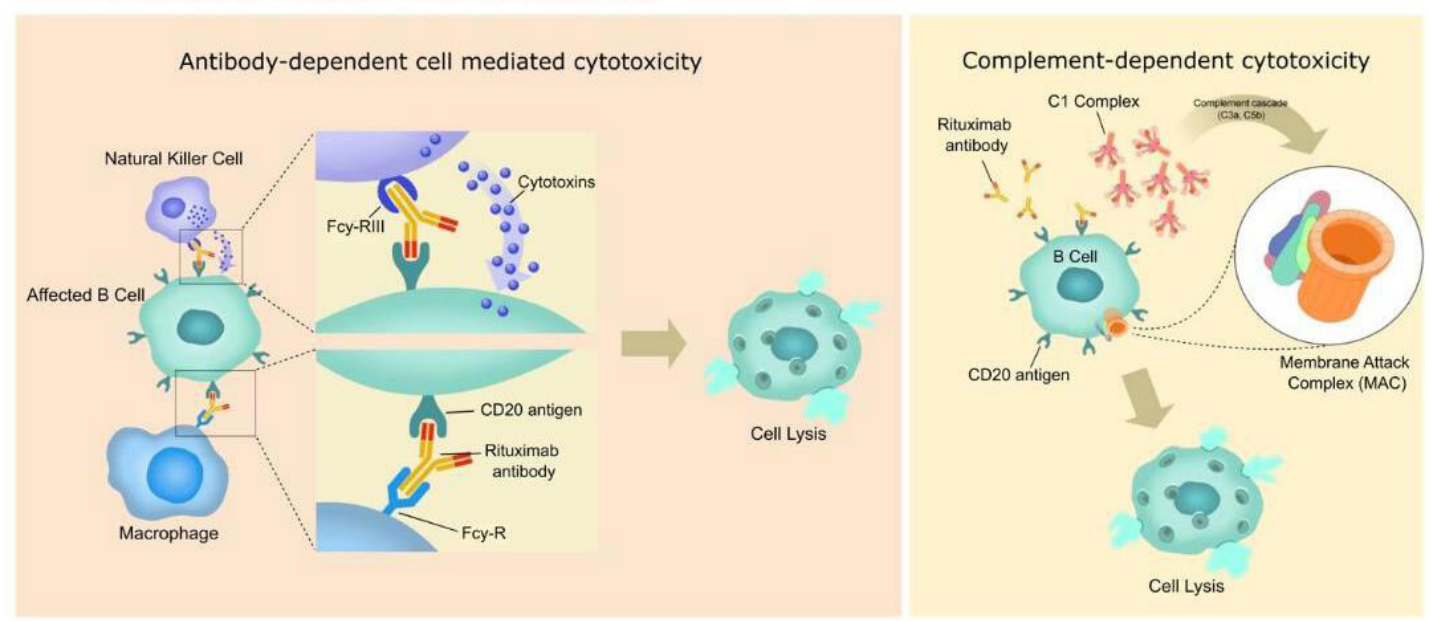

Figure 1 (A) describes the molecular structure of rituximab, including the weight of the chains and the binding affinity. (B) explains how rituximab uses antibody-dependent cell-mediated cytotoxicity and complement-dependent cytotoxicity (CDC), ultimately leading to cell lysis. This mechanism takes place with several effectors, macrophage, natural killer (NK) cells and neutrophils. In this figure, we focus on NK cells. Rituximab binds to the affected B cell (CD20) via the Fab portion and exposing the Fc region. The Fcy-RIII/CD16 receptor of NK cell binds to the Fc region of rituximab, forming a complex. Following its formation, the NK cell undergoes degranulation, releasing cytotoxins that mediate the lysis of the target cell. During the $C D C$, the rituximab antibody binds to the affected B cells (CD20) and causing activation of the complement cascade. This leads to the formation of the membrane attack complex, which induces cell lysis.

the complement cascade, leading to formation of the membrane attack complex, which induces cell lysis. ${ }^{12} 13$

Direct effects on abnormal B cell lymphocytes

The mechanism behind the direct effect of rituximab on abnormal B cell lymphocytes is not completely understood. Once the complex is formed, the affected cell may directly undergo apoptosis, inhibition of proliferation and cell cycle alteration. ${ }^{113}$

B cell depletion is likely to reduce the production of abnormal autoreactive antibodies, which explains its postulated utility in various autoimmune nephrology disorders.

\section{Effects on T cell lymphocytes}

As B cells produce costimulatory signals following activation for $\mathrm{T}$ cells and cytokines that modulate $\mathrm{T}$ cell differentiation, $\mathrm{B}$ cell depletion can be beneficial in T cell mediated disorders. In addition, some T cells may have CD20 receptors that allow for direct effects of rituximab. ${ }^{14}$ Moreover, rituximab has been shown to modulate $\mathrm{T}_{\text {reg }}$ and $\mathrm{B}_{\text {reg }}$ cells, which were recently discovered to influence disease relapse/recurrence in NS. ${ }^{15-17}$

\section{Direct action of rituximab on podocytes}

Rituximab has been shown to bind to sphingomyelinphosphodiesterase-acid-like-3b (SMPDL-3b) on the surfaces of 
podocytes that regulates acid-sphyngomyelinase activity and prevents disruption of the actin cytoskeleton and apoptosis of the podocyte. ${ }^{18}$ Although this mechanism is novel and interesting, its relevance in clinical use has been questioned after successful results in NS with other anti-CD20 antibodies that do not bind SMPDL-3b such as ofatumumab. ${ }^{19}$

\section{ROLE OF INTRAVENOUS RITUXIMAB IN PAEDIATRIC NEPHROLOGY}

\section{Nephrotic syndrome}

The utility of rituximab for paediatric NS was serendipitously discovered when a child with frequently relapsing/steroiddependent NS (FRNS/SDNS) was given rituximab for idiopathic thrombocytopaenic purpura. Alongside improved platelet counts, the sustained remission of NS was also noted. ${ }^{20}$ The excitement regarding this novel outcome was further reinforced by a case report, which demonstrated improvement in NS secondary to the recurrence of focal and segmental glomerulosclerosis (FSGS) post-transplantation, after receiving rituximab for posttransplant lymphoproliferative disorder (PTLD). ${ }^{21}$ Currently, although the mechanism of action for rituximab's therapeutic effects remains uncertain, it has become an important tool in the arsenal of the paediatric nephrologist. Proteinuria in NS may be mediated by a yet unrecognised permeability factor(s) of $\mathrm{T}$ cell cytokine origin, ${ }^{22}$ and as discussed before, this can be modulated through B cell depletion by rituximab. As also mentioned before, rituximab has been show to have direct podocyte stabilisation effects, although its clinical relevance has been questioned. ${ }^{18} 19$ Modulation of $\mathrm{T}_{\mathrm{reg}}$ and $\mathrm{B}_{\mathrm{reg}}$ cell populations by rituximab has also been correlated with relapses in NS. ${ }^{15}$ Delayed reconstitution of switched memory B cells following rituximab administration is postulated to predict an effective response to rituximab. ${ }^{16} \mathrm{Simi}$ larly, the reduced production of cytokine IFN-gamma+CD3+ by T cells at baseline in FSGS patients has been significantly associated with a longer time to relapse. ${ }^{17}$

Up to $50 \%$ of children with NS develop FRNS/SDNS and require steroid-sparing agents including cyclophosphamide, mycophenolate mofetil (MMF) and calcineurin inhibitors (CNIs) such as tacrolimus or ciclosporin. ${ }^{23}$ All of these medications have potential for serious adverse effects (SAEs), including the CNIinduced nephrotoxicity, and apart from cyclophosphamide, they need to be given over a prolonged period. Rituximab has shown significant steroid-sparing and CNI-sparing potential among FRNS/SDNS (table 1). In a recent review on FRNS/SDNS, the use of rituximab was shown to result in an average remission of 12-20 weeks, reduced frequencies of relapse and reduction or discontinuation of corticosteroids and other immunosuppressive agents. ${ }^{24}$ Its significant steroid-sparing effect has been demonstrated to improve growth parameters that are crucial in paediatric practice. ${ }^{25}$ Studies have flagged up certain attributes with some practical utility. Older age at rituximab administration has been significantly associated with improved outcomes, such as a lower risk of relapse, ${ }^{1026}$ longer time to $B$ cell recovery ${ }^{27}$ and lower risk of hypogammaglobulinaemia ${ }^{17}$; however, these associations have not been universally confirmed. ${ }^{1528}$ Despite its high cost, rituximab is postulated to be overall cost-effective as it may reduce the need for daily medications as well as the costs involved in regular drug level monitoring often needed for agents such as CNIs. ${ }^{29}$

In contrast to the significant benefit seen with rituximab among SDNS/FRNS, the jury is still out on its utility among SRNS (table 1). Despite the positive reports of cohort and registry studies, the recent International Paediatric Nephrology
Association guideline ${ }^{23}$ has given rituximab a weak recommendation (grade 2C) for use in SRNS in view of the negative results of the only randomised control trial (RCT) published to date..$^{30}$ In terms of response, the effect of rituximab among SRNS can be modulated by various variables including the period of assessment postrituximab therapy, concomitant use of corticosteroids and other immunosuppressive agents, disease progression and underlying aetiologies, particularly those secondary to genetic origin. Systematic reviews of cohort studies have shown that over $50 \%$ of SRNS children resistant to CNI do respond to rituximab and achieve either complete or partial remission. ${ }^{31}$ Currently, no alternative agent in comparison with rituximab demonstrates superior add-on efficacy among CNI-resistant SRNS. The role of rituximab should be considered as even partial remission (compared to no response) in SRNS has demonstrated a significantly better renal prognosis. ${ }^{32}$

\section{VASCULITIS}

As immune dysregulation and antibody production is postulated to play an important role in both AAV (granulomatosis with polyangiitis, microscopic polyangiitis and eosinophilic granulomatosis with polyangiitis) and SLE nephritis, the B cell depleting effect of rituximab is likely to be beneficial. AAV studies in adults, including RCTs, have demonstrated rituximab to be as effective as conventional therapy, obtaining remission in up to $80 \%$ of refractory patients. ${ }^{33}$ However, the same cannot be said for paediatric patients where the literature remains limited (table 2). ${ }^{34}$ Rituximab has been frequently used as an add-on for refractory cases in lupus nephritis and now is more routinely used even on initial presentation. A systematic review has shown that up to $33 \%$ of refractory lupus nephritis patients receiving rituximab show significant renal improvement including complete remission. ${ }^{35}$ However, add-on rituximab failed to show any benefit in the LUNAR trial, which was primarily an adult RCT for patients with lupus nephritis. ${ }^{36}$ However, retrospective data have consistently demonstrated it to be an effective add-on therapy with good steroid-sparing potential. ${ }^{37}$ Paediatric data in this field remain scarce and lack RCTs (table 2). Marks et al published the first series $(n=7)$ of successfully treated children in 2005 , which was subsequently updated to include 19 children in $2008{ }^{3839}$ Despite complex SLE, an impressive clinical response was observed with a large majority of children experiencing reduced disease activity and about $50 \%$ going into full remission with significantly improved British Isles Lupus Assessment Group index, antibody and complement levels and haematological and renal parameters. Basu $e t a l^{40}$ conducted a comparative study in childhood-onset lupus nephritis patients. A total of 44 lupus nephritis pediatric patients were followed for 36 months, who received either rituximab, MMF or cyclophopshmide along with oral prednisolone (tapering dose). Patients who received rituximab showed significantly higher flare-free survival period than MMF and cyclophosphamide $(\mathrm{p}=0.006)$. There was also a decrease in the required daily dose of prednisone in the rituximab group $(p=0.005)$. The authors concluded in favour of the relatively higher efficacy and medium safety of rituximab when compared with MMF or cyclophosphamide among children with lupus nephritis.

\section{KIDNEY TRANSPLANTATION}

As B cells play an important role in antibody-mediated rejection (ABMR), rituximab is likely to be useful. A meta-analysis by Macklin $e t \mathrm{al}^{41}$ on primarily adult studies concluded that rituximab may be of some benefit in acute ABMR. However, they 
Table 1 Relevant paediatric studies on use of rituximab in nephrotic syndrome (FRNS/SDNS and SRNS)

\begin{tabular}{|c|c|c|}
\hline Role of rituximab in & Type of studies & Commentaries \\
\hline $\begin{array}{l}\text { Idiopathic NS (SDNS/ } \\
\text { FRNS) }\end{array}$ & 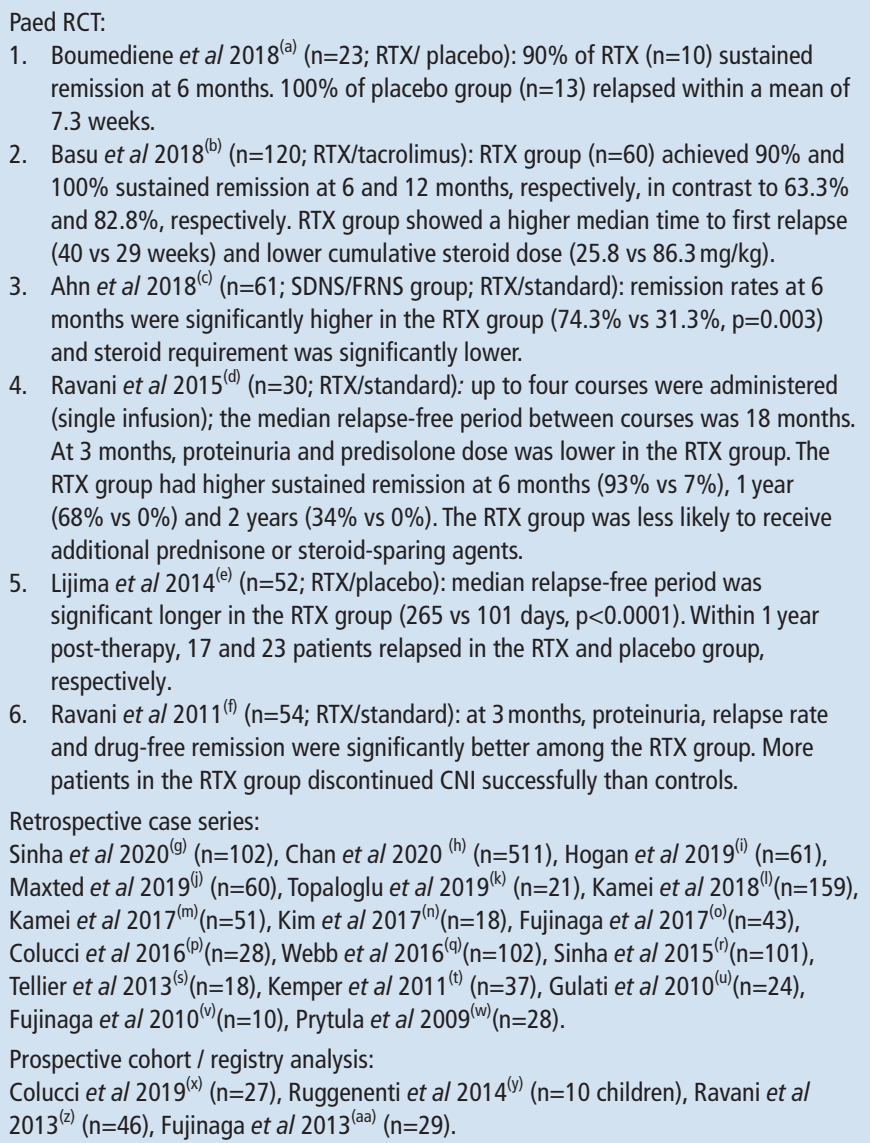 & $\begin{array}{l}\text { Among children with SDNS/FRNS, RTX in comparison with } \\
\text { placebo/standard therapy (steroids and CNIs), has been } \\
\text { associated with lower relapse rates, longer remission periods } \\
\text { in the midterm and onward and allows for greater reduction } \\
\text { or withdrawal of concomitant immunosuppressants (steroids } \\
\text { and CNI). } \\
\text { Younger age has been linked with higher rates of relapse and } \\
\text { shorter remission periods. The age of disease onset is less } \\
\text { commonly reported as a predictive factor of relapse; however, } \\
\text { renal histological changes that may occur from prolonged } \\
\text { proteinuria such as glomerulosclerosis also need to be taken } \\
\text { into consideration. }\end{array}$ \\
\hline
\end{tabular}

Note: (1) studies with cohort size $<10$ has been excluded. (2) RCT's results have been explained in detail.

References ( $a-z$ and $a a, b b, c c$, dd and ee) quoted in table 1 have been elaborated in the online supplemental references.

CNI, calcineurin inhibitor; CR, complete remission; FRNS, frequently relapsing nephrotic syndrome; PR, partial remission; RCT, randomised controlled trial; RTX, rituximab; SDNS,

steroid-dependent nephrotic syndrome; SRNS, steroid-resistant nephrotic syndrome.

also stressed the lack of high-quality evidence that precludes any firm conclusions. In chronic ABMR, rituximab did not appear to reliably improve outcomes. Although paediatric data are limited, a small $\mathrm{RCT}^{42}$ has supported the use of rituximab for acute ABMR (table 3).

Approximately, a third of post-KT for end-stage kidney disease secondary to FSGS has recurrence of FSGS. Despite a lack of RCTs, there are encouraging paediatric case reports/series that have demonstrated some benefit of rituximab, although in most cases, it was used as an add-on with plasmapheresis and other immunosuppressant that precludes a firm conclusion (table 3).

Rituximab has become a standard part of the preconditioning protocol for $\mathrm{ABO}$-incompatible (ABOi) transplantation (table 3). Maenosono et $\mathrm{al}^{43}$ conducted a retrospective study among 115 adults receiving ABOi living donor kidney transplantation (LDKT). The study was divided into two groups: 'good response' or 'poor response' to rituximab therapy with response defined as per CD19+ cells counts. Patient belonging to good 
Table 2 Relevant paediatric studies on use of rituximab in AAV and SLE nephritis

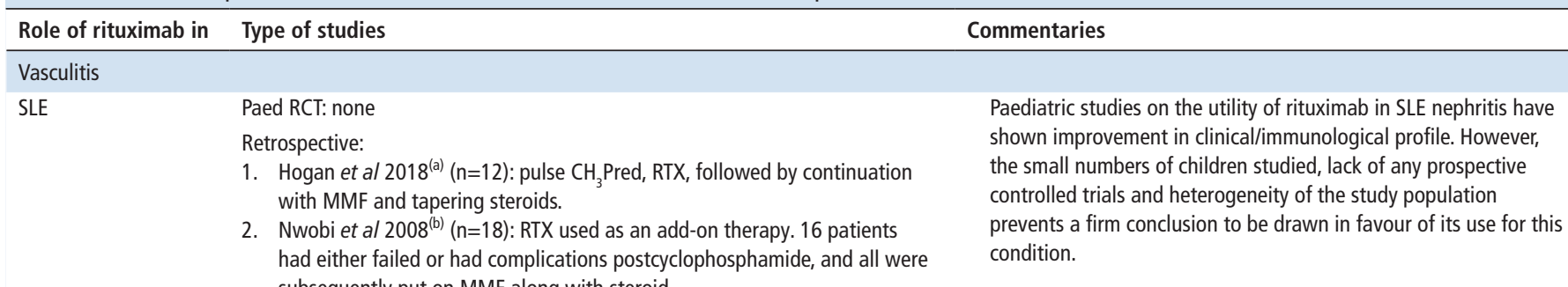
subsequently put on MMF along with steroid.

3. Podolskya et al $2007^{(c)}(n=19)$ : RTX given for refractory SLE for acute lifethreatening or organ-threatening disorders with various combination of presentation including renal, neurological and haematological.

4. Watson et al $2015^{(\mathrm{d})}(\mathrm{n}=63)$ : majority of patients had cyclophosphamide prior to rituximab. RTX was given as an add-on therapy with refractory SLE nephritis being the most common indication (36\% of all first courses).

5. Basu et al $2017^{(\mathrm{e})}(\mathrm{n}=44)$ : patients with active LN received RTX compared with MMF and CYC showed higher flare-free survival at 36 months $(p=0.006)$.

Prospective cohort: none.

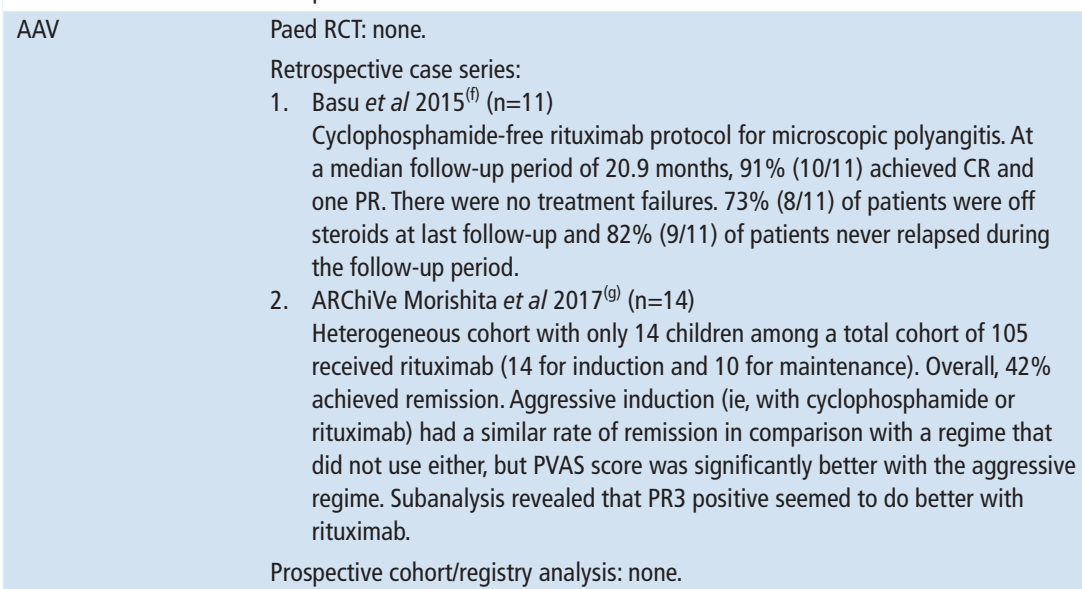

Although adult studies have shown promising results in the use of rituximab for AAV, paediatric data are limited to a few case series. Even in the ARChiVe cohort, very few children received rituximab, and any definite conclusion was further precluded because of the heterogeneity of the treatment protocol.

Note: (A) studies with cohort size $<10$ have been excluded.

References (a-f) quoted in table 2 have been elaborated in the online supplemental references.

$\mathrm{AAV}$, anca-associated vasculitis; CH3Pred, methyl prednisolone; CR, complete remission; MMF, mycophenolate mofetil; PR, partial remission; PVAS, paediatric vasculitis score; RCT, randomised controlled trial; RTX, rituximab; SLE, systemic lupus erythematosus.

response group showed less antibody-mediated rejection than the poor response group ( $8 \%$ vs $22.5 \%, \mathrm{p}=0.028$, respectively). Similarly, a retrospective paediatric study comparing the ABOi LDKT $(n=13)$ with ABO-compatible (ABOc) LDKT $(n=37)$ with rituximab use among ABOi LDKT showed encouraging results with similar graft outcome. However, the use of rituximab had a higher number of late-onset neutropenia in the ABOi group than the $\mathrm{ABOc}$ group $(\mathrm{p}<0.001)$, requiring granulocyte colony-stimulating factor. ${ }^{44}$

Rituximab has been shown to be effective in PTLD. ${ }^{45}$ Among 27 patients developing PTLD postallogenic human stem cell transplantation, 20 patients showed complete response with rituximab with a 1 -year overall survival of $46.8 \%{ }^{46}$

\section{DOSING OF RITUXIMAB}

The initial dosing regimen of 4 weekly intravenous infusions of rituximab at $375 \mathrm{mg} / \mathrm{m}^{2}$ was borrowed from the treatment protocol for lymphoma and PTLD. Whether this high dose is required for children with kidney disorders is a pertinent question. Recently, Chan et al ${ }^{10}$ published an international, multicentre retrospective review of 511 children with difficult SDNS/ FRNS followed up for at least 18 months postrituximab therapy. In this large cohort, they examined the effect of rituximab at three dosing levels: low $\left(375 \mathrm{mg} / \mathrm{m}^{2}\right)$, medium $\left(375 \mathrm{mg} / \mathrm{m}^{2} \times 2\right)$ and high $\left(375 \mathrm{mg} / \mathrm{m}^{2} \times 3-4\right)$, with or without maintenance immunosuppression. Although the low dose rituximab had a significant higher relapse risk and shorter relapse-free period, differences were insignificant if maintenance immunosuppression (either MMF or CNI) was continued following rituximab therapy. This study supported the possibility of reducing dose frequency under the cover of continued immunosuppression. Although this may reduce both the costs of additional rituximab and the risks of its associated side effects, prospective controlled trials are needed before accepting it as the standard protocol.

$\mathrm{B}$ cell depletion and its reconstitution have been used as a marker of response to rituximab. Fujinaga et $a l^{11}$ reported that early B cell recovery is associated with NS relapse, and most studies have shown that relapses usually occur after B cell reconstitution. However, there is no consensus regarding readministration of rituximab based on B cell recovery as not all children relapse once $\mathrm{B}$ cells repopulate. ${ }^{25}$ Measuring peripheral B cells (CD19 or CD20) may not demonstrate what is happening in the renal $\mathrm{B}$ cell population, and some units employ 6 monthly intravenous rituximab infusions irrespective of peripheral B cells counts in order to minimise or allow no immunosuppression in some patients groups (eg, adults with lupus nephritis). Registry data are required to capture the long-term effects of repeated doses of rituximab. NS relapses have also been associated with 
Table 3 Relevant paediatric studies on the use of rituximab in kidney transplantation

\begin{tabular}{|c|c|c|}
\hline Role of rituximab in & Type of studies & Commentaries \\
\hline \multicolumn{3}{|l|}{ Transplantation } \\
\hline $\begin{array}{l}\text { Antibody mediated Acute } \\
\text { Rejection }\end{array}$ & $\begin{array}{l}\text { Paed RCT: } \\
\text { 1. Zarkhin et al } 2008^{(a)} \text { ( } n=20 ; \text { RTX versus standard-of-care } \\
\text { immunosuppression, thymoglobulin and/or pulse steroids) for } \\
\text { treatment of biopsy-confirmed acute transplant rejection with B } \\
\text { cell infiltrates. Some benefits noted in recovery of graft function } \\
(\mathrm{p}=0.026) \text { and improvement of biopsy rejection scores at } 1 \text {-month } \\
(\mathrm{p}=0.0003) \text { and } 6 \text {-month }(\mathrm{p}<0.0001) \text { follow-up biopsies. C4d } \\
\text { deposition was not seen on follow-up biopsies after RTX therapy } \\
\text { but was seen in } 30 \% \text { of control patients. There was no change in } \\
\text { DSA in either group. } \\
\text { Retrospective case series: Kranz et al } 2011^{(b)}(n=3) \text {, Towmbley et al } \\
2013^{(c)}(n=3) \text { and Gulleroglu et al } 2013^{(\mathrm{d})}(\mathrm{n}=7) \text {. } \\
\text { Prospective cohort/registry analysis: none. }\end{array}$ & $\begin{array}{l}\text { Although RTX is used widely in B cell mediated acute rejection, supporting } \\
\text { evidence is scarce. Most of the paediatric reports are small case series. } \\
\text { Although we have a single paediatric RCT }{ }^{(a)} \text { as well as adult case series } \\
\text { showing promising results, the larger adult RCT such as the RITUX ERAH } \\
\text { study did not show any benefit of adding RTX to the standard plasma } \\
\text { exchange, immunoglobulin and corticosteroid at } 1 \text { year or } 7 \text { years follow- } \\
{\text { up. }{ }^{(k, 1)}}\end{array}$ \\
\hline $\begin{array}{l}\text { Post-transplantation FSGS } \\
\text { recurrence }\end{array}$ & $\begin{array}{l}\text { Paed RCT: none } \\
\text { Retrospective case series: Sethna et al } 2011^{(\mathrm{e})}(n=4) \text {, Grenda et al } \\
2016^{(f)}(n=5) \text {, Kumar et al } 2012^{(\mathrm{gg})}(\mathrm{n}=8) \text { and Dello Strologo et al } \\
2016^{(\mathrm{h})}(\mathrm{n}=15) \text {. } \\
\text { Prospective cohort/registry analysis: none. }\end{array}$ & $\begin{array}{l}\text { Paediatric evidence is limited to only small case series with conflicting } \\
\text { results and reports incidents of serious side effects. }\end{array}$ \\
\hline $\mathrm{ABOi}$ transplantation & $\begin{array}{l}\text { Retrospective case series: Hamasaki et al } 2019^{(i)}(n=21) \text {, Kawamura et } \\
\text { al } 2020^{(j)}(n=13) \text { and Aikawa et al } 2014^{(k)}(n=89) .\end{array}$ & $\begin{array}{l}\text { Supplemented primarily by adult series, rituximab has become a standard } \\
\text { protocol for ABOi transplantation. }\end{array}$ \\
\hline
\end{tabular}

Note: (A) RCT's results have been explained in detail.

References (a-I) quoted in table 3 have been elaborated in the online supplemental references.

$A B O i, A B O$ incompatible; DSA, donor specific antibody; FSGS, focal and segmental glomerulosclerosis; RCT, randomised control trial; RTX, rituximab.

significant drops in $\mathrm{T}_{\text {reg }}$ cells and alteration in IL-2 expression, accompanied with reconstitution of switched memory B cells. ${ }^{15} 17$ The relevance of these biomarkers in guiding subsequent dosing needs to be further explored.

\section{ADMINISTRATION OF RITUXIMAB}

Prior to giving rituximab, some centres advocate investigations to rule out coexisting pulmonary tuberculosis (primarily in an endemic region) and test hepatitis B surface antigen. Children receiving rituximab are usually admitted to the hospital for a day, receiving premedication of chlorphenamine or hydroxyzine $(0.5-1 \mathrm{mg} / \mathrm{kg}$ orally maximal at $100 \mathrm{mg})$, intravenous methylprednisolone $(1 \mathrm{mg} / \mathrm{kg}$ maximal at $50 \mathrm{mg})$, paracetamol $(10-15 \mathrm{mg} / \mathrm{kg}$ orally as required every 4 hours maximal at $1 \mathrm{~g})$ and ondansetron $(0.15 \mathrm{mg} / \mathrm{kg} /$ dose orally or intravenously maximal at $8 \mathrm{mg}$ ), administered $30 \mathrm{~min}$ before rituximab infusion. Rituximab is diluted to $1-4 \mathrm{mg} / \mathrm{mL}$ in $0.9 \%$ sodium chloride and administered initially at approximately $1 \mathrm{~mL} / \mathrm{kg} /$ hour (maximum of $50 \mathrm{~mL} /$ hour), which is increased hourly by $1 \mathrm{~mL} /$ $\mathrm{kg}$ with close monitoring for any adverse reaction.

\section{IMMUNISATION POSTRITUXIMAB}

Children receiving rituximab are usually immunocompromised due to B cell suppression and prone to various infections including those secondary to vaccine-preventable diseases. Unfortunately, the immunity among these children is often impaired even prior to rituximab administration, as they are likely to be on prolonged use of immunosuppressive agents. Their compromised immunity has quite commonly precluded an adequate response to vaccination and the use of live vaccines. Rituximab blunts both humoral and cellular response that influences vaccination schedules. Postrituximab B cell counts start to recover from 3 months onward but may take up to 12 months or longer to fully normalise. Although plasma cells initially produce antibodies, it is proposed that $\mathrm{B}$ cell depletion eventually decreases the overall production. Therefore, until B cell repopulation and restoration of normal antibody production occurs, vaccines are unlikely to be fully effective. Most centres are continuing to use rituximab during the COVID-19 pandemic, without increased risk of infection having been demonstrated in children, but there may be reduced response when vaccinations are introduced globally.

In the absence of publications on immunisation efficacy in renal disorders among children receiving rituximab, most of the conclusions are drawn from vaccination studies following rituximab use in rheumatological disorders. ${ }^{47}$ Although there is no universal accepted guideline, it is reasonable to agree on some basic points:

a. With the exception of live vaccines, it is advisable to adhere to local guidelines irrespective of the underlying condition.

b. Attempts should be made to ensure that all non-live vaccines are given at least 1 week before rituximab infusion.

c. Live vaccines should be given at least 1 month prior to rituximab infusion, provided the child is not on any other immunosuppressants.

d. Vaccination can be recommenced 6 months postrituximab, where the restoration of $\mathrm{B}$ cell populations and the ability to mount seroprotection are likely to have occurred.

e. Live vaccines can also be given 6-9 months postrituximab provided the child is not on any other immunosuppressants.

f. As the response to tetanus, vaccination may be decreased with rituximab, especially within the first 6 months of treatment, it is recommended that the tetanus immunoglobulin be administered if there is high risk of a contaminated wound.

Although rituximab impairs development of new immunity postvaccination, existing immunity may not be influenced significantly. ${ }^{47}$

\section{CHEMOPROPHYLAXIS OF POSTRITUXIMAB THERAPY}

Patients on rituximab are at higher risk of Pneumocystis jiroveci pneumonia, and some centres advocate the use of antibiotic prophylaxis (usually cotrimoxazole) until B cell recovery. ${ }^{23}$ 


\begin{tabular}{|c|c|}
\hline \multicolumn{2}{|l|}{ Immediate side effects } \\
\hline Acute infusion reaction & $\begin{array}{l}\text { Most commonly seen in patients receiving treatment for the first time. It typically occurs within } 2 \text { hours of starting the therapy. The patient } \\
\text { may present with anaphylaxis-like symptoms, pain, fever, chills, rash, pruritus, angioedema, shortness of breath and hypotension. In these } \\
\text { situations, the infusion speed needs to be reduced with supportive therapy (intravenous saline, acetaminophen and diphenhydramine), and } \\
\text { severe reactions may require epinephrine. The risk of infusion reactions drops significantly during the consecutive infusions. However, if the } \\
\text { patient has a history of hypersensitivity type one or anaphylactic reaction to murine proteins, rituximab infusion is contraindicated. }\end{array}$ \\
\hline \multicolumn{2}{|c|}{ Other systemic side effects } \\
\hline Central nervous system & Headache, dizziness and fever. \\
\hline Cardiovascular & Hypotension or hypertension, myocardial infarction, atrial fibrillation, ventricular tachycardia and supraventricular tachycardia. \\
\hline Respiratory & Cough, dyspnoea, pneumonia, bronchospasm and bronchiolitis obliterans. \\
\hline Gastrointestinal & Nausea, vomiting, diarrhoea and abdominal pain. \\
\hline Hepatic & Elevated ALT and rarely hepatic failure. \\
\hline Renal & Electrolyte imbalance like hypophosphataemia, hypocalcaemia, peripheral oedema and renal failure. \\
\hline Immunological & $\begin{array}{l}\text { Hypogammaglobulinaemia. } \\
\text { Infection (bacterial, viral and fungal): sepsis, febrile infection, herpes zoster, acute bronchitis and sinusitis. }\end{array}$ \\
\hline Haematology & Leucopenia, thrombocytopaenia and and neutropaenia. \\
\hline
\end{tabular}

$\mathrm{ALT}$, alanine transaminase.

\section{ADVERSE EFFECTS OF RITUXIMAB}

Majority of studies on rituximab use in paediatric nephrology have reported an acceptable safety profile but caution is still warranted; a report from France showed mortality in 5 out of 98 subjects of NS within a year of rituximab. ${ }^{48}$

Infusion reactions appear to be the most common side effects (table 4) at an incidence of $9.1 \%-56.3 \%$, typically occurring within $30-120$ min of starting infusion. ${ }^{624}$ Fortunately, reactions are usually mild and improve with temporary discontinuation if needed. Infusions can often be restarted at a slower rate under antihistamine and corticosteroid cover, unless anaphylaxis is suspected.

Infections remain the other concern (table 4). As rituximab spares plasma cells, serum immunoglobulin levels are typically normal, although persistent hypogammaglobulinaemia has been occasionally reported. In a long-term study on idiopathic NS, prolonged depletion of switch memory B cells and younger age at initial administration were significantly associated with low immunoglobulin levels following anti-CD20 treatment. ${ }^{17}$ Serious infections reported in both case reports/series and cohort studies are not very common. A meta-analysis of three RCTs of rituximab therapy in rheumatoid arthritis did not show any significant increase in the incidence of infections. ${ }^{49}$ In contrast, the use of rituximab in lymphomas has been associated with double the increased risk of neutropaenia and infection as well as potential reactivation of hepatitis $\mathrm{B}$, resulting in fulminant hepatic failure. ${ }^{1}$ Late neutropaenia has been occasionally reported among NS along with associated complications such as infections with $P$. jiroveci. ${ }^{6}$ Although rare and not yet reported among primary renal disorders, a concern is the risk of progressive multifocal leucoencephalopathy, an encephalitis caused by JC polyomavirus and characterised by the gradual onset of cognitive impairment, motor weakness, speech problems and deterioration in vision. ${ }^{623}$ Another rare serious adverse event is the development of rituximab-associated lung injury. ${ }^{52}$ This usually occurs after multiple rituximab infusions (from 1 to 12 with mean of 4) and about $1-3$ months after the last infusion. Pathologically, it is characterised by bronchiolitis obliterans organising pneumonia, interstitial pneumonitis, acute respiratory distress syndrome and hypersensitivity pneumonitis. Repeated doses of rituximab have been associated with the development of human antichimeric antibodies, which may cause anaphylactic reaction or decrease the efficiency of rituximab by increasing its clearance.

\section{OTHER MONOCLONAL ANTIBODIES}

Humanised anti-CD20 and anti-CD22 monoclonal antibodies such as ofatumumab/ocrelizumab and epratuzumab, respectively, have been developed and studied. Belimumab, a human monoclonal antibody that inhibits the B cell activating factor, also known as B lymphocyte stimulator, has been developed as a specific drug for SLE. Recently, it has been shown to be effective in childhood lupus, ${ }^{50}$ and although children with severe active lupus nephritis were excluded, improvement was noted among those patients with lupus nephritis who were included in the study.

\section{CONCLUSION}

Rituximab has opened new avenues in the treatment of multiple paediatric nephrology disorders. Its effectiveness has been demonstrated in refractory NS, and it is likely to be useful among children with antibody-mediated nephrology disorders, particularly AAV and lupus nephritis and also in the field of KT. Slow infusion under a standard protocol with constant monitoring is important as infusion reactions are common. Despite its demonstrated utility, caution is justified as some studies have reported significant SAEs and the long-term outcomes remain unclear. Multiple questions need to be further explored, including the optimal frequency of redosing in NS, the monitoring requirement postrituximab (including monitoring of total leucocyte count, liver function test, CD19 and immunoglobulin levels) and the immunisation schedule following rituximab therapy.

Contributors Both RS and NA should be credited as joint first author.

Funding This project was supported by the National Institute for Health Research Biomedical Research Centre at Great Ormond Street Hospital for Children National Health Service Foundation Trust and University College London.

Competing interests None declared.

Patient consent for publication Not required.

Provenance and peer review Not commissioned; externally peer reviewed. Data availability statement No data are available.

Supplemental material This content has been supplied by the author(s). It has not been vetted by BMJ Publishing Group Limited (BMJ) and may not have been peer-reviewed. Any opinions or recommendations discussed are solely those of the author(s) and are not endorsed by BMJ. BMJ disclaims all liability and responsibility arising from any reliance placed on the content. Where the content includes any translated material, BMJ does not warrant the accuracy and reliability of the translations (including but not limited to local regulations, clinical guidelines, 
terminology, drug names and drug dosages), and is not responsible for any error and/or omissions arising from translation and adaptation or otherwise.

Open access This is an open access article distributed in accordance with the Creative Commons Attribution Non Commercial (CC BY-NC 4.0) license, which permits others to distribute, remix, adapt, build upon this work non-commercially, and license their derivative works on different terms, provided the original work is properly cited, appropriate credit is given, any changes made indicated, and the use is non-commercial. See: http://creativecommons.org/licenses/by-nc/4.0/.

\section{ORCID iDs}

Nirav Agrawal http://orcid.org/0000-0002-3102-7228

Yuanxin Xue http://orcid.org/0000-0002-4371-8210

Rahul Chanchlani http://orcid.org/0000-0001-9366-3118

Stephen D Marks http://orcid.org/0000-0001-9850-8352

\section{REFERENCES}

1 Salles G, Barrett M, Foà R, et al. Rituximab in B-cell hematologic malignancies: a review of 20 years of clinical experience. Adv Ther 2017;34:2232-73.

2 Cragg MS, Walshe CA, Ivanov AO, et al. The biology of CD20 and its potential as a target for mAb therapy. Curr Dir Autoimmun 2005;8:140-74.

3 Hofmeister JK, Cooney D, Coggeshall KM. Clustered CD20 induced apoptosis: Srcfamily kinase, the proximal regulator of tyrosine phosphorylation, calcium influx, and caspase 3-dependent apoptosis. Blood Cells Mol Dis 2000;26:133-43.

4 Semac I, Palomba C, Kulangara K, et al. Anti-Cd20 therapeutic antibody rituximab modifies the functional organization of rafts/microdomains of $B$ lymphoma cells. Cancer Res 2003;63:534-40.

5 Rituximab Genentech. Available: https://www.accessdata.fda.gov/drugsatfda_docs/ label/1997/ritugen112697-lab.pdf [Accessed 30 Sep 2020].

6 Sinha A, Bagga A. Rituximab therapy in nephrotic syndrome: implications for patients' management. Nat Rev Nephrol 2013;9:154-69.

7 Kamei K, Ito S, Nozu K, et al. Single dose of rituximab for refractory steroid-dependent nephrotic syndrome in children. Pediatr Nephrol 2009;24:1321-8.

8 Regazzi MB, lacona I, Avanzini MA, et al. Pharmacokinetic behavior of rituximab: a study of different schedules of administration for heterogeneous clinical settings. Ther Drug Monit 2005;27:785-92.

9 Pan S, Yu H, Surti A, et al. Pharmacodynamics of rituximab on B lymphocytes in paediatric patients with autoimmune diseases. Br J Clin Pharmacol 2019;85:1790-7.

10 Chan EY-hin, Webb H, Yu E, et al. Both the rituximab dose and maintenance immunosuppression in steroid-dependent/frequently-relapsing nephrotic syndrome have important effects on outcomes. Kidney Int 2020;97:393-401.

11 Fujinaga S, Nishino T, Umeda C, et al. Long-Term outcomes after early treatment with rituximab for Japanese children with cyclosporine- and steroid-resistant nephrotic syndrome. Pediatr Nephrol 2019;34:353-7.

12 Wang W, Erbe AK, Hank JA. Nk cell-mediated antibody-dependent cellular cytotoxicity in cancer immunotherapy. Front Immunol 2015;6:368.

13 Weiner GJ. Rituximab: mechanism of action. Semin Hematol 2010;47:115-23.

14 Mélet J, Mulleman D, Goupille $\mathrm{P}$, et al. Rituximab-Induced T cell depletion in patients with rheumatoid arthritis: association with clinical response. Arthritis Rheum 2013:65:2783-90

15 Bhatia D, Sinha A, Hari P, et al. Rituximab modulates T- and B-lymphocyte subsets and urinary CD80 excretion in patients with steroid-dependent nephrotic syndrome. Pediatr Res 2018;84:520-6.

16 Chan C-Y, Liu ID, Resontoc LP, et al. T lymphocyte activation markers as predictors of responsiveness to rituximab among patients with FSGS. CJASN 2016;11:1360-8.

17 Colucci M, Carsetti R, Serafinelli J, et al. Prolonged impairment of immunological memory after anti-CD20 treatment in pediatric idiopathic nephrotic syndrome. Front Immunol 2019;10:1653.

18 Fornoni A, Sageshima J, Wei C, et al. Rituximab targets podocytes in recurrent focal segmental glomerulosclerosis. Sci Transl Med 2011;3:85ra46.

19 Wang C-S, Liverman RS, Garro R, et al. Ofatumumab for the treatment of childhood nephrotic syndrome. Pediatr Nephrol 2017;32:835-41.

20 Benz K, Dötsch J, Rascher W, et al. Change of the course of steroid-dependent nephrotic syndrome after rituximab therapy. Pediatr Nephrol 2004;19:794-7.

21 Pescovitz MD, Book BK, Sidner RA. Resolution of recurrent focal segmental glomerulosclerosis proteinuria after rituximab treatment. $N$ Eng/ J Med 2006;354:1961-3

22 Wei C, Trachtman H, Li J, et al. Circulating suPAR in two cohorts of primary FSGS. J Am Soc Nephrol 2012;23:2051-9.

23 Trautmann A, Vivarelli M, Samuel S, et al. IPNA clinical practice recommendations for the diagnosis and management of children with steroid-resistant nephrotic syndrome. Pediatr Nephrol 2020:35:1529-61.

24 Kallash M, Smoyer WE, Mahan JD. Rituximab use in the management of childhood nephrotic syndrome. Front Pediatr 2019;7:178.
25 Sinha R, Banerjee S, Mukherjee A, et al. Impact of rituximab on anthropometric indices among childhood steroid-dependent nephrotic syndromes. Arch Dis Child 2021;106:283-5

26 Fujinaga S, Hirano D, Mizutani A, et al. Predictors of relapse and long-term outcome in children with steroid-dependent nephrotic syndrome after rituximab treatment. Clin Exp Nephrol 2017;21:671-6.

27 Hogan J, Dossier C, Kwon T, et al. Effect of different rituximab regimens on B cell depletion and time to relapse in children with steroid-dependent nephrotic syndrome. Pediatr Nephrol 2019;34:253-9.

28 lijima K, Sako M, Nozu K, et al. Rituximab for childhood-onset, complicated, frequently relapsing nephrotic syndrome or steroid-dependent nephrotic syndrome: a multicentre, double-blind, randomised, placebo-controlled trial. Lancet 2014;384:1273-81

29 Takura T, Takei T, Nitta K. Cost-Effectiveness of administering rituximab for steroiddependent nephrotic syndrome and frequently relapsing nephrotic syndrome: a preliminary study in Japan. Sci Rep 2017;7:46036.

30 Magnasco A, Ravani P, Edefonti A, et al. Rituximab in children with resistant idiopathic nephrotic syndrome. JASN 2012;23:1117-24.

31 Kamei K, Ishikura K, Sako M, et al. Rituximab therapy for refractory steroid-resistant nephrotic syndrome in children. Pediatr Nephrol 2020;35:17-24.

32 Trautmann A, Schnaidt S, Lipska-Ziętkiewicz BS, et al. Long-term outcome of steroidresistant nephrotic syndrome in children. JASN 2017;28:3055-65.

33 Guerry M-JCJ, Brogan P, Bruce IN, et al. Recommendations for the use of rituximab in anti-neutrophil cytoplasm antibody-associated vasculitis. Rheumatology 2012:51:634-43.

34 Lee JJY, Alsaleem A, Chiang GPK, et al. Hallmark trials in ANCA-associated vasculitis (AAV) for the pediatric rheumatologist. Pediatr Rheumatol Online J 2019;17:31.

35 Mahmoud I, Jellouli M, Boukhris I, et al. Efficacy and safety of rituximab in the management of pediatric systemic lupus erythematosus: a systematic review. J Pediatr 2017; 187:213-9

36 Rovin BH, Furie R, Latinis $\mathrm{K}$, et al. Efficacy and safety of rituximab in patients with active proliferative lupus nephritis: the lupus nephritis assessment with rituximab study. Arthritis Rheum 2012;64:1215-26.

37 Yuan Z, Xie Q, Wu X, Qifang X, Xiaochuan W, et al. Rituximab treatment for lupus nephritis: a systematic review. CIM 2020;43:E47-54.

38 Marks SD, Patey S, Brogan PA, et al. B lymphocyte depletion therapy in children with refractory systemic lupus erythematosus. Arthritis Rheum 2005;52:3168-74.

39 Podolskaya A, Stadermann M, Pilkington C, et al. B cell depletion therapy for 19 patients with refractory systemic lupus erythematosus. Arch Dis Child 2008;93:401-6.

40 Basu B, Roy B, Babu BG. Efficacy and safety of rituximab in comparison with common induction therapies in pediatric active lupus nephritis. Pediatr Nephrol 2017:32:1013-21.

41 Macklin PS, Morris PJ, Knight SR. A systematic review of the use of rituximab for the treatment of antibody-mediated renal transplant rejection. Transplant Rev 2017:31:87-95.

42 Zarkhin V, Li L, Kambham N, et al. A randomized, prospective trial of rituximab for acute rejection in pediatric renal transplantation. Am J Transplant 2008;8:2607-17.

43 Maenosono R, Unagami K, Kakuta Y, et al. Association between response to rituximab and antibody-mediated rejection in ABO-incompatible living kidney transplantation. Int J Urol 2019:26:1114-20.

44 Kawamura T, Hamasaki Y, Takahashi Y, et al. Abo-Incompatible pediatric kidney transplantation without antibody removal. Pediatr Nephrol 2020;35:95-102.

45 Kanzelmeyer NK, Maecker-Kolhoff B, Zierhut H, et al. Graft outcomes following diagnosis of post-transplant lymphoproliferative disease in pediatric kidney recipients: a retrospective study. Transpl Int 2018;31:367-76.

46 Zhu C-Y, Zhao S-S, Wang X-K, et al. Outcome of Rituximab-Based treatment for post-transplant lymphoproliferative disorder after allogeneic hematopoietic stem cell transplantation: a single-center experience. Ann Transplant 2019;24:175-84.

47 Cheng DR, Barton R, Greenway A, et al. Rituximab and protection from vaccine preventable diseases: applying the evidence to pediatric patients. Expert Rev Vaccines 2016:15:1567-74.

48 Trivin C, Tran A, Moulin B, et al. Infectious complications of a rituximab-based immunosuppressive regimen in patients with glomerular disease. Clin Kidney $\mathrm{J}$ 2017;10:461-9.

49 Lee YH, Bae S-C, Song GG. The efficacy and safety of rituximab for the treatment of active rheumatoid arthritis: a systematic review and meta-analysis of randomized controlled trials. Rheumatol Int 2011;31:1493-9.

50 Brunner HI, Abud-Mendoza C, Viola DO, et al. Safety and efficacy of intravenous belimumab in children with systemic lupus erythematosus: results from a randomised, placebo-controlled trial. Ann Rheum Dis 2020;79:1340-8.

51 Bitzan M, Anselmo M, Carpineta L. Rituximab (B-cell depleting antibody) associated lung injury (RALI): a pediatric case and systematic review of the literature. Pediatr Pulmonol 2009;44:922-34. 